\title{
Influences of Waiting Time on Driver Behaviors While Implementing In-Vehicle Traffic Light for Priority-Controlled Unsignalized Intersections
}

\author{
Bo Yang, ${ }^{1}$ Rencheng Zheng, ${ }^{1}$ Tsutomu Kaizuka, ${ }^{1}$ and Kimihiko Nakano ${ }^{2}$ \\ ${ }^{1}$ Institute of Industrial Science, The University of Tokyo, 4-6-1 Komaba, Meguro-ku, Tokyo, Japan \\ ${ }^{2}$ Interfaculty Initiative in Information Studies, The University of Tokyo, 4-6-1 Komaba, Meguro-ku, Tokyo, Japan \\ Correspondence should be addressed to Bo Yang; b-yang@iis.u-tokyo.ac.jp
}

Received 12 May 2017; Revised 3 September 2017; Accepted 14 September 2017; Published 17 October 2017

Academic Editor: Chunjiao Dong

Copyright (C) 2017 Bo Yang et al. This is an open access article distributed under the Creative Commons Attribution License, which permits unrestricted use, distribution, and reproduction in any medium, provided the original work is properly cited.

\begin{abstract}
In-vehicle traffic lights that assist drivers in crossing intersections are in development; however, the availability of the in-vehicle traffic light will be limited if the waiting time of a vehicle is not considered in actual traffic conditions, especially at prioritycontrolled unsignalized intersections that normally consist of one major and two minor roads. The present study therefore investigated the effects of the waiting time on driver behaviors to improve the in-vehicle traffic light for the priority-controlled unsignalized intersections. Gap acceptance theory that considers the waiting time was adopted in the implementation of the invehicle traffic light, to assist minor-road drivers in passing through the intersections by selecting appropriate major-road gaps. A driving simulator experiment involving 12 participants was performed for the minor and major roads, by applying the in-vehicle traffic light with and without the consideration of waiting time. Results demonstrate that the maximum acceleration strokes of minor-road vehicles were significantly reduced, indicating a lower possibility of aggressive driving when the in-vehicle traffic light was applied while considering the waiting time. Meanwhile, an improved steering stability was observed from the driver behaviors at the intersections, as the maximum lateral acceleration of minor-road vehicles significantly decreased when the waiting time was considered.
\end{abstract}

\section{Introduction}

There are thousands of accidents yearly at priority-controlled unsignalized intersections, which are one of the most common types of unsignalized intersections [1]. We previously proposed an in-vehicle traffic light based on the application of vehicular communications, displaying virtual traffic light information inside vehicles to assist drivers in safely crossing priority-controlled unsignalized intersections [2, 3]. However, the practicality of the in-vehicle traffic light at prioritycontrolled unsignalized intersections will be greatly limited if the waiting time of vehicles in actual traffic conditions is not considered. The present study thus aims to improve the invehicle traffic light by including the waiting time in the implementation of the system and performs driving simulator experiments to investigate the effects on driver behaviors when the in-vehicle traffic light considering waiting time is included.

A priority-controlled unsignalized intersection normally consists of a major road without a stop line and two minor roads that are controlled by stop lines. Vehicles on the major road are permitted to cross the intersection without stopping. In contrast, minor-road vehicles have to stop completely at the stop line first, waiting for an appropriate major-road gap to enter the intersection. Previous studies pointed out that one major problem of priority-controlled unsignalized intersections was that many drivers had difficulty in judging adequate gaps $[4,5]$. Most accidents at priority-controlled unsignalized intersections were due to driver errors, especially the failures of minor-road drivers in selecting a proper 
gap on the major road [6]. The American Association of State Highway and Transportation Officials therefore identified that the use of new technologies that assist drivers in judging gaps at priority-controlled unsignalized intersections is an important initiative in addressing intersection accidents [7].

Several methods have been proposed to assist drivers at priority-controlled unsignalized intersections [8-10]. Researchers from the Minnesota Department of Transportation developed an infrastructure-based system to help minorroad drivers make better decisions at rural unsignalized intersections, where multiple surveillance sensors were applied to track vehicles moving along the major road [11, 12]. Most of the technologies studied require comparatively high costs of infrastructure investment, including the installation of sensors at intersections.

$\mathrm{V}-2-\mathrm{X}$ communication technologies have great potential for collecting information at priority-controlled unsignalized intersections, in that they have low deployment costs and wide operating distances. Given the application of vehicular communications, a novel concept of providing virtual traffic light information on the windshield has been presented [13, 14]. Traffic simulations have verified that traffic efficiency might be improved with virtual traffic lights [15-18].

To apply the concept of the virtual traffic light at prioritycontrolled unsignalized intersections, we proposed an invehicle traffic light system in our previous driving simulator studies according to gap acceptance theory [2, 3]. Gap acceptance theory was used to decide whether a major-road gap was appropriate for the entry of a minor-road vehicle [19]. According to the theory, the smallest major-road gap that ensures minor-road vehicles can safely cross intersections is referred to as the critical gap [20].

Previous studies considered the critical gap to be $6.5 \mathrm{~s}$ [21]. However, it was reported that the waiting time at intersections had a notable effect on the gap acceptance behaviors of drivers [22]. It was observed that minor-road drivers preferred to accept smaller gaps to enter intersections earlier if they had waited for a long time [23]. Other studies indicated that the longer a driver waited, the more the driver was willing to accept risks and the higher the likelihood the driver accepted a shorter gap $[24,25]$. The critical gap should therefore not be considered a constant value. In fact, it would first decrease with waiting time and then converge to a constant value [26].

It remains unclear how driver behaviors are affected by the waiting time in the case of the implementation of an in-vehicle traffic light. The objective of the present study was therefore to analyze the effects on driver behaviors of the application of in-vehicle traffic lights considering the waiting time at priority-controlled unsignalized intersections.

The present paper firstly proposes the in-vehicle traffic light with consideration of the waiting time for prioritycontrolled unsignalized intersections and then details driving simulator experiments. Results and findings on driving operations and eye behaviors are then presented and discussed. The paper concludes with the implications of the results of the study.

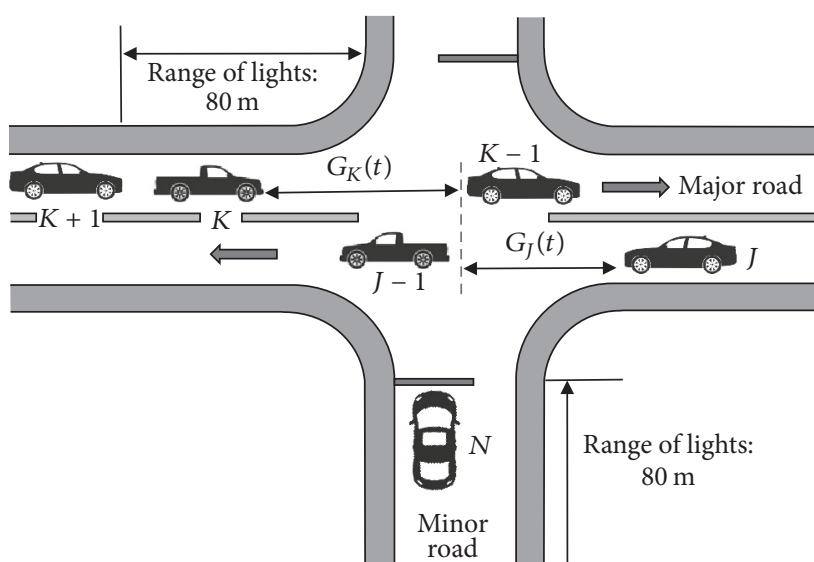

FIGURE 1: Gaps on the major road at a priority-controlled unsignalized intersection.

\section{Methodology}

To apply the waiting time in the implementation of an in-vehicle traffic light system, the modelling of prioritycontrolled unsignalized intersections, including the definition of the major-road gap, is firstly performed. An invehicle traffic light system is then proposed according to gap acceptance theory, in which the critical gap is decided considering the waiting time.

2.1. Modelling of Priority-Controlled Unsignalized Intersections. For a priority-controlled unsignalized intersection, as presented in Figure 1, when a minor-road vehicle $N$ arrives at an intersection, the gaps on the major road can be defined as

$$
\begin{gathered}
G_{K}(t)=\frac{d_{K}(t)}{v_{K}(t)}, \\
G_{J}(t)=\frac{d_{J}(t)}{v_{J}(t)},
\end{gathered}
$$

where $d_{K}(t)$ and $d_{J}(t)$ are the distances to the intersection and $v_{K}(t)$ and $v_{J}(t)$ are the velocities of major-road vehicles $K$ and $J$ at time $t$, respectively.

The major-road gap $G_{N}(t)$ for vehicle $N$ will then be determined according to the vehicle's direction of motion, as shown in Table 1.

By comparing the major-road gap $G_{N}(t)$ with the critical gap $G_{C}$, the operation of a priority-controlled unsignalized intersection for vehicle $N$ can then be expressed as

$$
\begin{aligned}
& P_{U}(t)+P_{V}(t)=1, \\
& P_{U}(t)=\left\{\begin{array}{ll}
1, & G_{N}(t)<G_{C}, \\
0, & G_{N}(t) \geq G_{C},
\end{array} P_{V}(t)= \begin{cases}1, & G_{N}(t) \geq G_{C}, \\
0, & G_{N}(t)<G_{C}\end{cases} \right.
\end{aligned}
$$

where $P_{U}(t)$ and $P_{V}(t)$ represent the priority statuses of major- and minor-road vehicles, respectively. $P_{U}(t)=1$ means that the major-road vehicles have priority in crossing the intersection while $P_{V}(t)=1$ means that the minor-road vehicle has priority in crossing. 
TABLE 1: Major-road gap for minor-road vehicle $N$.

\begin{tabular}{lc}
\hline Direction of vehicle & Gap \\
\hline Forward & $G_{N}(t)=\min \left(G_{K}(t), G_{J}(t)\right)$ \\
Left turn & $G_{N}(t)=G_{J}(t)$ \\
Right turn & $G_{N}(t)=\min \left(G_{K}(t), G_{J}(t)\right)$ \\
\hline
\end{tabular}

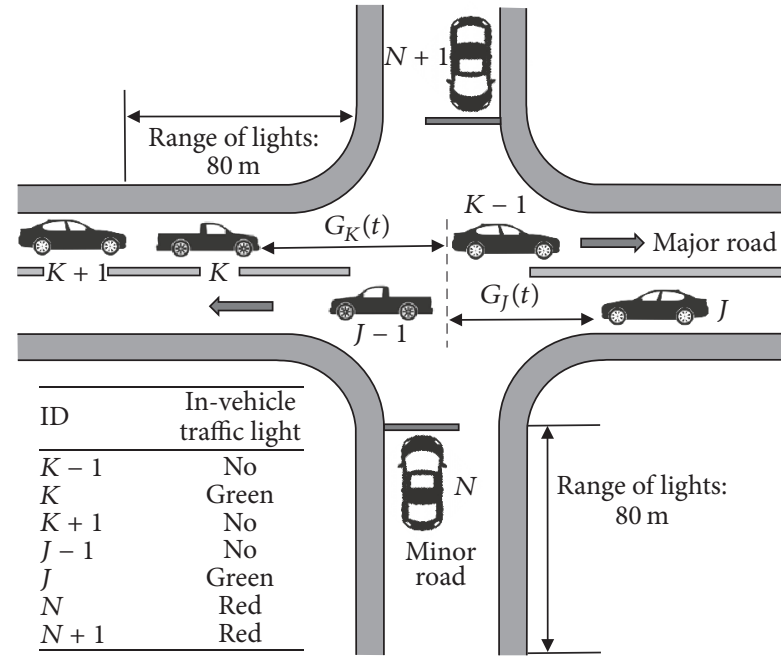

Figure 2: In-vehicle traffic lights at a priority-controlled unsignalized intersection when major-road gaps are smaller than the critical gap.

2.2. In-Vehicle Traffic Light considering the Waiting Time. As explained in the above section, the critical gap $G_{C}$ will be affected by the waiting time of minor-road vehicles at intersections. According to the data from observational studies including [26], the critical gap is $6.5 \mathrm{~s}$ if drivers wait for less than $10 \mathrm{~s}, 5.5 \mathrm{~s}$ if the waiting time falls within 10 to $20 \mathrm{~s}, 5.25 \mathrm{~s}$ if the waiting time falls within 20 to $30 \mathrm{~s}$, and $5 \mathrm{~s}$ if the waiting time is longer than $30 \mathrm{~s}$. The relationship between the waiting time and critical gap at priority-controlled unsignalized intersections can therefore be expressed as

$$
\begin{aligned}
G_{C}(T)= & 6.5-H(T-10)-0.25 \times H(T-20)-0.25 \\
& \times H(T-30),
\end{aligned}
$$

where $G_{C}(T)$ is the critical gap considering the waiting time and $T$ is the waiting time of a minor-road vehicle; the value of $6.5 \mathrm{~s}$ is the critical gap when the waiting time is less than $10 \mathrm{~s} ; H(T-10), H(T-20)$, and $H(T-30)$ are Heaviside step functions that represent the scenarios that drivers have waited for 10 to $20 \mathrm{~s}, 20$ to $30 \mathrm{~s}$, and longer than $30 \mathrm{~s}$, respectively; and 0.25 is a parameter for adjusting the critical gap according to the changes in waiting time.

Figure 2 shows that, for a minor-road vehicle $N$ approaching the priority-controlled unsignalized intersection, the state of the vehicle will be checked in real time to confirm whether the vehicle has arrived at the stop line. If the vehicle has arrived at the stop line, the in-vehicle traffic light system will start recording its waiting time and checking whether an oncoming minor-road vehicle exists. If an oncoming vehicle
TABLE 2: Example of a waiting list for minor-road vehicles.

\begin{tabular}{lccc}
\hline ID & Role & Direction & Rank \\
\hline$N$ & Leader & Right turn & 1st \\
$N+1$ & Follower & Forward & 2nd \\
\hline
\end{tabular}

exists, the earlier minor-road vehicle will be selected as the leader, and a waiting list will be created to manage the minorroad vehicles waiting at the stop lines.

An example of the waiting list is shown in Table 2, according to the traffic condition presented in Figure 2. Minor-road vehicle $N$ reaches the intersection earlier than vehicle $N+1$ and is therefore selected as the leader. If vehicle $N$ wishes to make a right turn and turns on its right blinker while vehicle $N+1$ plans to move forward, it is possible for vehicles $N$ and $N+1$ to collide at the intersection as their planned paths intersect. Vehicle $N+1$ is thus ranked second and will not enter the intersection together with vehicle $N$.

According to the above considerations of the rank and major-road gap, for minor-road vehicle $N$, an in-vehicle traffic light considering the waiting time $L_{N}(t)$ can be designed as

$$
\begin{aligned}
& L_{N}(t)=-H\left(80-d_{N}(t)\right)+R_{N}(t) \times P_{N}(t), \\
& R_{N}(t)=\left\{\begin{array}{ll}
2, & \text { Rank }=1 \text { st }, \\
0, & \text { Rank } \neq 1 \text { st },
\end{array} P_{N}(t)= \begin{cases}0, & G_{N}(t)<G_{C}(T), \\
1, & G_{N}(t) \geq G_{C}(T),\end{cases} \right.
\end{aligned}
$$

where $R_{N}(t)$ and $P_{N}(t)$ are functions for judging the rank and major-road gap of vehicle $N$, respectively; $L_{N}(t)=-1$ represents a red light, $L_{N}(t)=0$ means that no light is displayed, and $L_{N}(t)=1$ represents a green light; and $H(80-$ $\left.d_{N}(t)\right)$ is a Heaviside step function and $d_{N}(t)$ is the distance from vehicle $N$ to the intersection.

For a major-road vehicle $K$, as shown in Figure 2, the invehicle traffic light considering the waiting time $L_{K}(t)$ can be expressed as

$$
\begin{array}{r}
L_{K}(t)=H\left(80-d_{K}(t)\right)+P_{K}(t), \\
P_{K}(t)= \begin{cases}0, & G_{N}(t)<G_{C}(T), \\
1, & G_{N}(t) \geq G_{C}(T),\end{cases}
\end{array}
$$

where $P_{K}(t)$ is the function applied in judging the entry of the minor-road vehicle for vehicle $K ; L_{K}(t)=0$ means that no light is displayed, $L_{K}(t)=1$ represents a green light, and $L_{K}(t)=2$ represents a flashing yellow light that warns majorroad drivers to proceed with caution; and $H\left(80-d_{K}(t)\right)$ is a Heaviside step function and $d_{K}(t)$ is the distance from vehicle $K$ to the intersection.

An example of the in-vehicle traffic light considering the waiting time is shown in Figure 2, where major-road gaps are smaller than the critical gap. For vehicle $K+1$ that has not entered the range of the in-vehicle traffic light, or vehicles $K-1$ and $J-1$ that have crossed the intersection, no invehicle traffic light will be displayed. For minor-road vehicles in the range of the in-vehicle traffic light, including vehicle $N$, a red light will be displayed, requiring the vehicle to stop 


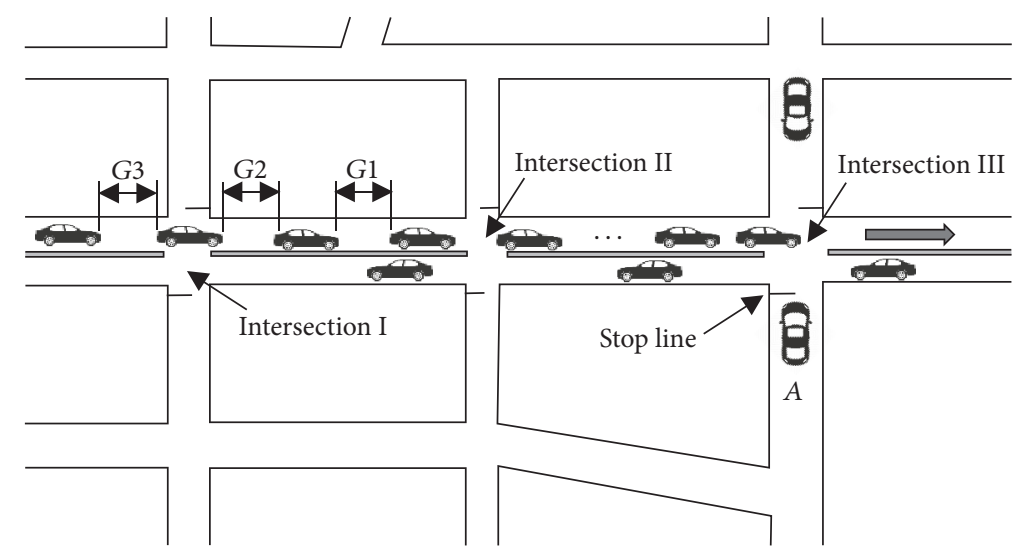

FIGURE 3: Driving scenario of the minor-road experiment with the participants in vehicle $A$.

at the stop line. Afterwards, the minor-road vehicles need to wait for a safe major-road gap to enter the intersection. If a safe gap appears, the light presented to the minor-road vehicle will turn green. For major-road vehicles that have entered the range of the in-vehicle traffic light, including vehicle $K$, a green light will be displayed if no minor-road vehicle is allowed to enter the intersection. If the entry of a minor-road vehicle is permitted, the in-vehicle traffic light displayed to major-road vehicles will become a flashing yellow light.

\section{Experimental Study}

3.1. Participants. Twelve males, ranging in age from 20 to 30 years (average of 24.5 years), participated in the study. All participants had a valid driving license and reported that their health did not adversely affect their driving performance. They had been driving for 4.7 years on average (range of 1 year to 8 years) and had a mean driving frequency of 1.2 times per week (range of once to three times per week).

3.2. Apparatus. An advanced driving simulator was used to produce realistic driving sensations for the participants. The simulator was composed of a motion platform with six degrees of freedom and a display system with a 140-degree forward field of view.

The in-vehicle traffic light system was mainly composed of a laptop computer and an iHUD head-up display (Springteq Electronics Corporation, New Taipei, Taiwan). The laptop computer was connected with the driving simulator via an Ethernet cable. During the experiments, the updated traffic information in the driving simulator, including the positions and velocities of vehicles, was transferred to the laptop computer in real time. The program of the in-vehicle traffic light, which was installed on the laptop computer, used the obtained information to judge the intersection conditions and to decide which light should be displayed. Finally, the light was presented to the participants via the head-up display, which was positioned according to guidelines for the placement of in-vehicle display systems [27].
3.3. Experimental Conditions. It was expected that the driving performances of minor-road drivers would be affected if their waiting times were considered by the in-vehicle traffic light system. Meanwhile, the driving safety of major-road drivers should also be assessed as the minor-road vehicles were allowed to enter intersections with smaller major-road gaps when considering the waiting time. Therefore, minorroad experiments and a major-road experiment were prepared for all participants to evaluate their driving behaviors.

3.3.1. Minor-Road Experiment. In the minor-road experiment, the participants were required to drive vehicle $A$ to complete a right turn at intersection III. As shown in Figure 3, to analyze the effects of the waiting time, a congested majorroad traffic flow was designed such that the participants waited for longer than $30 \mathrm{~s}$. The congested major-road traffic flow comprised 10 vehicles and could be described with three parameters: (1) the speeds of the vehicles were set to $40 \mathrm{~km} / \mathrm{h}$, (2) the time headways between the vehicles were constant values between 2 and $4 \mathrm{~s}$, which prevented the possible entry of minor-road vehicle $A$ before the gaps $G 1, G 2$, and $G 3$, when no in-vehicle traffic light was provided, and (3) the traffic flow rate during the experiment period was 900 vehicles/hour. Following the congested major-road traffic flow, three majorroad gaps $G 1, G 2$, and $G 3$ were provided as chances for the participants to cross the intersection.

To avoid learning effects, three orders of presentation of G1, G2, and G3 were prepared as shown in Table 3. Meanwhile, three assistance conditions were provided for each participant as presented in Table 4. The orders of G1, G2, and $G 3$ and the assistance conditions were combined for the participants, considering counterbalancing.

3.3.2. Major-Road Experiment. For major-road drivers, the in-vehicle traffic light was expected to warn them of the entry of minor-road vehicles at intersections. According to the relationship between the critical gap and waiting time as shown in (3), the shortest critical gap for the minor-road vehicles was $5 \mathrm{~s}$ if the waiting time was longer than $30 \mathrm{~s}$. 


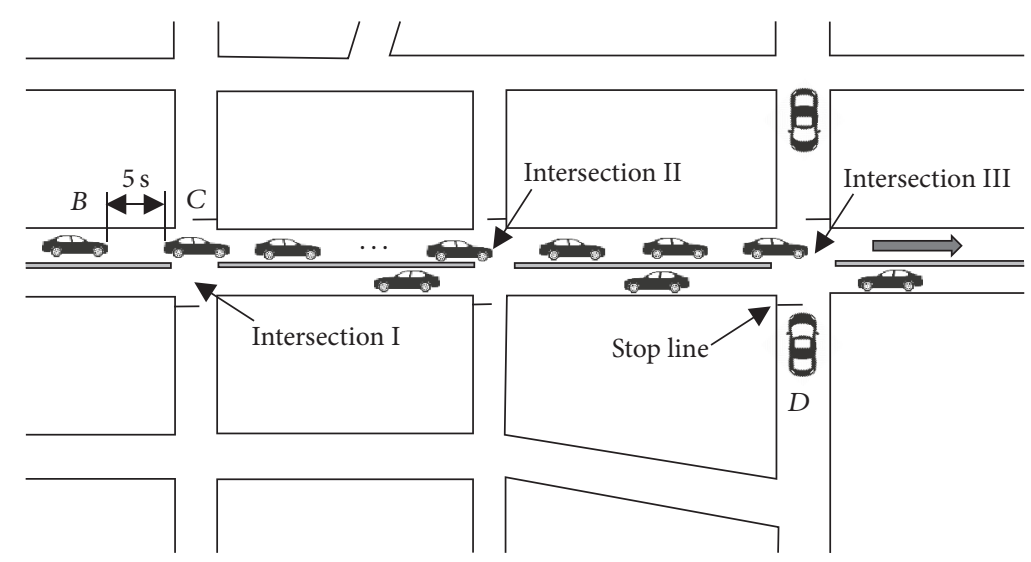

FIgURE 4: Driving scenario of the major-road experiment with the participants in vehicle $B$.

TABLE 3: Orders of major-road gaps.

\begin{tabular}{lccc}
\hline Gap & Order 1 & Order 2 & Order 3 \\
\hline$G 1$ & $5.5 \mathrm{~s}$ & $6.0 \mathrm{~s}$ & $6.5 \mathrm{~s}$ \\
$G 2$ & $6.0 \mathrm{~s}$ & $6.5 \mathrm{~s}$ & $6.0 \mathrm{~s}$ \\
G3 & $6.5 \mathrm{~s}$ & $5.5 \mathrm{~s}$ & $5.5 \mathrm{~s}$ \\
\hline
\end{tabular}

TABLE 4: Assistance conditions of the minor-road experiment.

\begin{tabular}{lr}
\hline Number & Condition \\
\hline$(1)$ & Without in-vehicle traffic light \\
$(2)$ & In-vehicle traffic light without considering waiting time \\
(3) & In-vehicle traffic light considering waiting time \\
\hline
\end{tabular}

For assessment of the driving safety of major-road drivers, the driving scenario of the major-road experiment is presented in Figure 4. Participants were in major-road vehicle $B$. Another major-road vehicle $C$ was set to keep a constant gap of $5 \mathrm{~s}$ with vehicle $B$ until vehicle $C$ crossed intersection III, which was expected to offer a chance to minor-road vehicle $D$ waiting at intersection III to enter. The majorroad vehicles before vehicle $C$ ensured that vehicle $D$ waited for longer than $30 \mathrm{~s}$. Similar to the case of the minor-road experiment, congested major-road traffic flow comprised 10 vehicles including vehicle $C$. The speeds of the vehicles were limited to $40 \mathrm{~km} / \mathrm{h}$ and the traffic flow rate was 900 vehicles/hour. Meanwhile, constant time headways between 2 and $4 \mathrm{~s}$ were maintained. After vehicle $C$ crossed intersection III, minor-road vehicle $D$ accepted the gap between vehicles $B$ and $C$ and entered the intersection. The participants were required to react and avoid collisions with vehicle $D$.

The assistance conditions of the major-road experiment are presented in Table 5. As the gap of $5 \mathrm{~s}$ would not be accepted by the in-vehicle traffic light without considering the waiting time, the driver behaviors were analyzed under only two conditions.

3.4. Measured Variables and Evaluation Indexes. Driving data, including the positions, velocities, and acceleration of all vehicles, were recorded with the driving simulator.
TABLE 5: Assistance conditions in the major-road experiment.

\begin{tabular}{lc}
\hline Number & Condition \\
\hline$(1)$ & Without in-vehicle traffic light \\
$(2)$ & In-vehicle traffic light considering waiting time \\
\hline
\end{tabular}

Meanwhile, eye-gaze data were measured with a Smart Eye Pro system (Smart Eye AB, Gothenburg, Sweden).

Four indexes were applied to evaluate driver behaviors in the minor-road experiment: the maximum acceleration stroke, blink rate, maximum lateral acceleration, and postencroachment time. The postencroachment time, maximum brake stroke, and perception response time were used for the major-road experiment.

The maximum acceleration stroke represented the maximum extent of the acceleration pedal stroke of vehicle $A$, when the participants turned right at intersection III, ranging from 0 to 1 . The data were automatically recorded by the driving simulator during the experiments.

The blink rate was calculated from the waiting time of the participants at intersection III and the number of blinks during that period. The data of blink were recorded with the Smart Eye system which consisted of three cameras and two flashes. Before the experiment, adjustments and precalibrations of the eye-gaze tracking measurement were performed for every participant. The precalibration mainly comprised camera calibration, gaze calibration, and ninepoint calibration. For camera calibration, the orientations, apertures, and focuses of the cameras were adjusted to keep the faces of the participants clearly positioned in the center of each image taken by the cameras. All the participants were then required to look around the three cameras and their personal profiles for eye-gaze tracking were created according to the snapshots taken by the cameras. To better recognize the eye-gaze, the profiles were optimized, especially for marking the inner and outer corners of the eyes. The gaze calibration was then performed for the three cameras to check the accuracy of the gaze calibration. Finally, a nine-point calibration was conducted to ensure the realtime detection of the visual point throughout the measuring 
process. Moreover, if a deterioration in the performance of eye-gaze tracking was observed during the experiment, a recalibration could be performed to ensure a high-quality continuous measurement. Based on the accurate eye-gaze tracking data, all samples that belonged to a blink were marked with a blink id in the output data by the system. Meanwhile, the system had a filter that detected blinks by evaluating the measured eyelid opening samples over a period of approximately $700 \mathrm{~ms}$, which means that blinks that lasted longer than $700 \mathrm{~ms}$ were not considered as blinks. Therefore, the obtained number of blinks had already been filtered automatically and could be considered reliable for evaluation.

Maximum lateral acceleration was the extreme value of lateral acceleration when vehicle $A$ turned right at intersection III. The data of lateral acceleration were automatically recorded by the driving simulator during the experiments.

The postencroachment time was the elapsed time between the departure of a leading vehicle and the arrival of an oncoming vehicle in a conflict area. A shorter elapsed time between the departure of a leading vehicle and the arrival of an oncoming vehicle suggests greater risk of collision. The postencroachment time was chosen as a safety indicator at intersections for the following reasons that it was reported to be one of the best measures applying to the angle conflicting events, and a low value of postencroachment time indicates an encounter with high severity [28-30].

The postencroachment time $T_{P}$ can be calculated as

$$
T_{P}=\frac{S_{i}(t)}{v_{i}(t)},
$$

where $S_{i}(t)$ and $v_{i}(t)$ are the distance to the conflict area and the velocity of the oncoming vehicles, respectively.

In the minor-road experiment, minor-road vehicle $A$ driven by the participants was the leading vehicle, and the arrival of the oncoming vehicle was actually controlled by the driving simulator; therefore, the values of postencroachment time were determined objectively and deemed suitable for describing the urgency of the situation. In the major-road experiment, major-road vehicle $B$ driven by the participants acted as the oncoming vehicle. It was possible that the participants might choose to brake severely for a larger postencroachment time to satisfy their subjective safety margin. Therefore, the maximum brake stroke variable was applied for evaluating the driving safety together with the postencroachment time.

Maximum brake stroke represented the maximum extent of brake pedal stroke of the vehicle $B$, ranging from 0 to 1 . It was automatically recorded by the driving simulator during the experiments.

The perception response time was defined as the total time, in seconds, elapsed from the entry of minor-road vehicle $D$ to the depression of the brake pedal of major-road vehicle $B$, as shown in Figure 4 .

3.5. Subjective Evaluations. Feelings of frustration and task difficulty were evaluated in the minor-road experiment. The

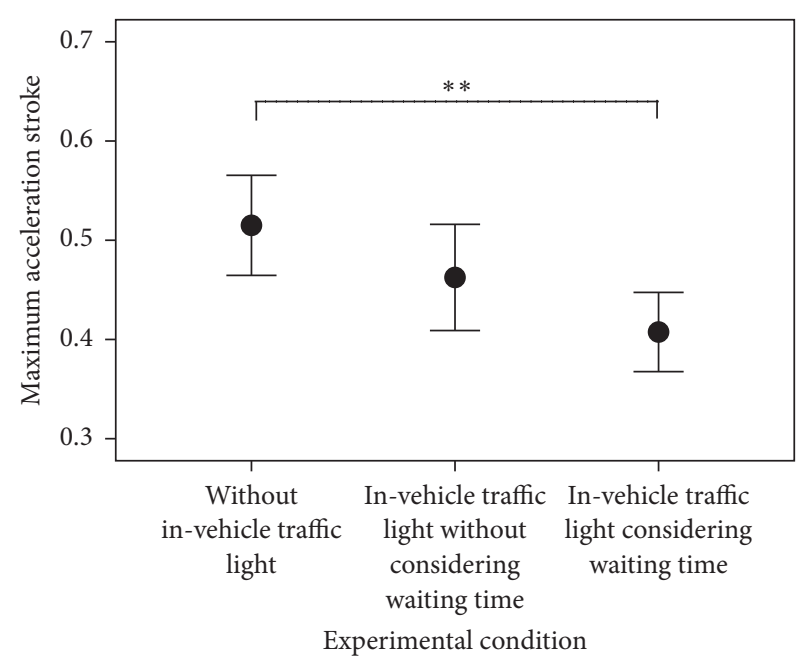

FIGURE 5: Results of the maximum acceleration stroke in the minorroad experiment. $* *$ indicates a significant difference at $p<0.01$ in statistical analysis.

feeling of safety was assessed in the major-road experiment. Evaluation scores were collected using a five-pointscale measurement questionnaire at the conclusion of each experimental session.

3.6. Data Analysis. Statistical analysis was conducted to determine whether the consideration of waiting time significantly affected the driver behaviors and subjective evaluations for the 12 participants. The significance level was set at 0.05 .

A one-way repeated measures ANOVA was conducted for the driver behaviors including the maximum acceleration stroke, blink rate, maximum lateral acceleration, postencroachment time, and perception response time.

A Wilcoxon signed-rank test was performed for the subjective evaluations.

\section{Results}

\subsection{Driver Behaviors}

4.1.1. Maximum Acceleration Stroke. The maximum acceleration stroke was used in the minor-road experiment to analyze the acceleration behaviors of the participants at intersection III. A higher maximum acceleration stroke indicates a higher possibility of aggressive driving.

Figure 5 shows that there was no significant difference in the maximum acceleration stroke between the conditions of there being no in-vehicle traffic light and there being an in-vehicle traffic light without considering the waiting time, although a decreasing trend was observed. The result for the in-vehicle traffic light considering the waiting time was significantly different from the result without an in-vehicle traffic light $(p=0.001<0.05)$.

4.1.2. Blink Rate. The blink rate was used to analyze the driver condition in the minor-road experiment. A higher blink rate 


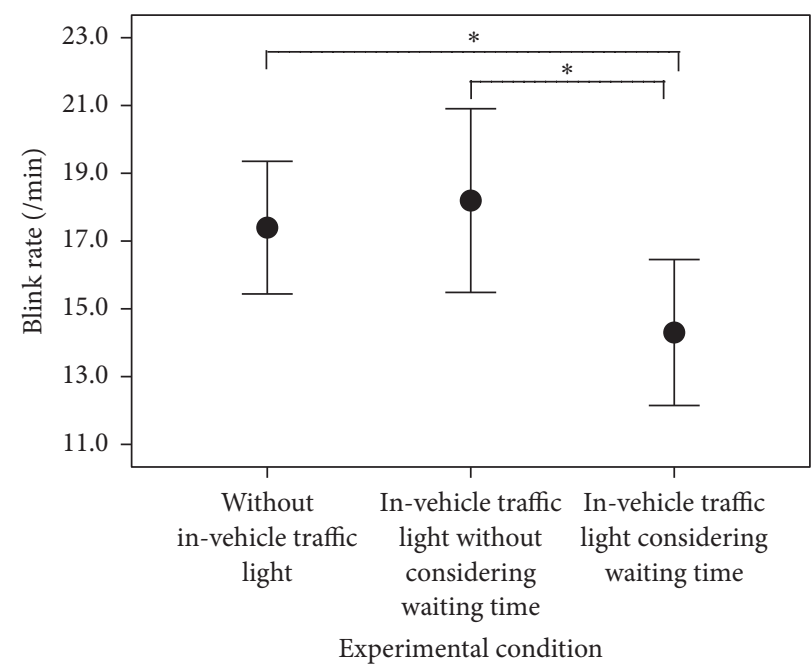

FIGURE 6: Results of the blink rate in the minor-road experiment. * indicates a significant difference at $p<0.05$ in statistical analysis.

might be considered the result of frustration. Figure 6 shows that when the in-vehicle traffic light considering the waiting time was applied, the blink rate was significantly lower than that for the in-vehicle traffic light without considering the waiting time $(p=0.033<0.05)$. Meanwhile, a significant difference in the blink rate was observed between the conditions of no in-vehicle traffic light and the provision of the in-vehicle traffic light while considering the waiting time ( $p=0.044<0.05)$. There was no significant difference between the provision of no in-vehicle traffic light and that of the in-vehicle traffic light without considering the waiting time.

4.1.3. Maximum Lateral Acceleration. The maximum lateral acceleration was used to evaluate the steering stability in the minor-road experiment. A lower value of maximum lateral acceleration indicates better steering performance. Figure 7 shows that the maximum lateral acceleration of the minorroad vehicle was significantly lower when using the in-vehicle traffic light while considering the waiting time than when using the in-vehicle traffic light without considering the waiting time $(p=0.049<0.05)$. A significant difference was also observed between the conditions of no in-vehicle traffic light and the provision of the in-vehicle traffic light without considering the waiting time $(p=0.043<0.05)$.

4.1.4. Postencroachment Time. The postencroachment time was calculated to evaluate the driving safety in both the minor-road and major-road experiments. The results of the minor-road experiment are presented in Figure 8(a). The application of the in-vehicle traffic light while considering the waiting time significantly increased the postencroachment time, compared with the case of no in-vehicle traffic light ( $p=$ $0.01<0.05)$. Meanwhile, there was no significant difference in the postencroachment time between the provisions of the in-vehicle traffic light with and without the consideration of waiting time. The results of the major-road experiment

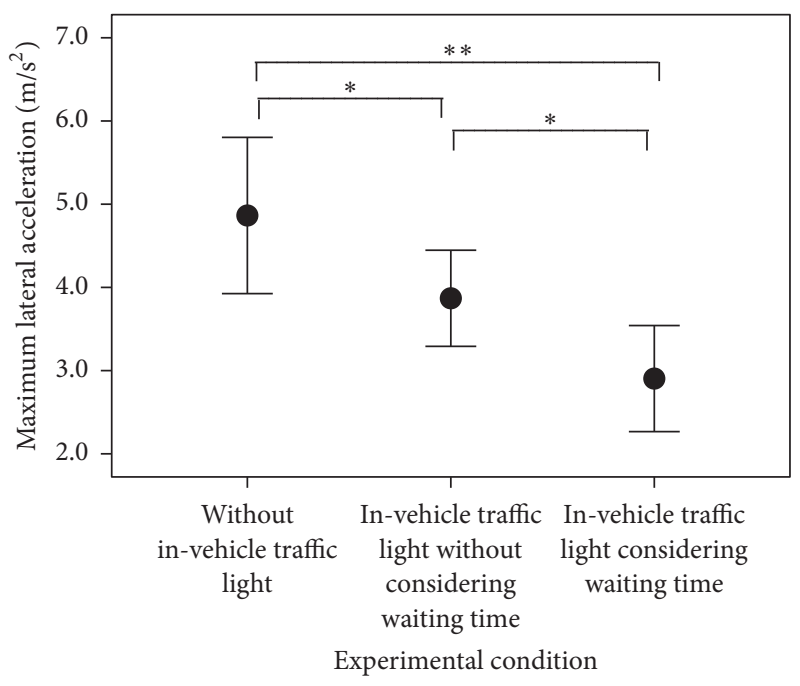

FIGURE 7: Results of maximum lateral acceleration in the minorroad experiment. $* *$ and $*$ indicate a significant difference at $p<$ 0.01 and $p<0.05$ in statistical analysis, respectively.

are shown in Figure 8(b). When the in-vehicle traffic light with consideration of the waiting time was adopted, the postencroachment time significantly improved to have a mean value of $5.5 \mathrm{~s}$, compared with the case of no in-vehicle traffic light $(p=0.037<0.05)$.

A longer postencroachment time indicates a lower possibility of collision at intersections. It therefore suggests that the driving safety in the minor-road experiment might not be significantly affected by consideration of the waiting time. The results of the major-road experiment imply that the driving safety of major-road drivers could be ensured when the shortest critical gap of $5 \mathrm{~s}$ was accepted by minor-road vehicles with the application of the in-vehicle traffic light considering the waiting time.

4.1.5. Maximum Brake Stroke. The maximum brake stroke was used to analyze the braking behaviors in the major-road experiment. Figure 9 shows that, for the maximum brake stroke in the major-road experiment, there was a significant effect of providing the in-vehicle traffic light $(p=0.047<$ 0.05 ), which indicates that the maximum brake stroke could be significantly reduced by the usage of in-vehicle traffic light.

4.1.6. Perception Response Time. The perception response time was applied to evaluate the driver reactions to the entry of minor-road vehicles in the major-road experiment. A shorter perception response time indicates a faster reaction to the entry of minor-road vehicles. Figure 10 shows that the perception response time significantly reduced when the invehicle traffic light considering the waiting time was used $(p=0.002<0.05)$.

\subsection{Subjective Evaluations}

4.2.1. Evaluation of Frustration. Frustration was evaluated to analyze the driver condition in the minor-road experiment. 


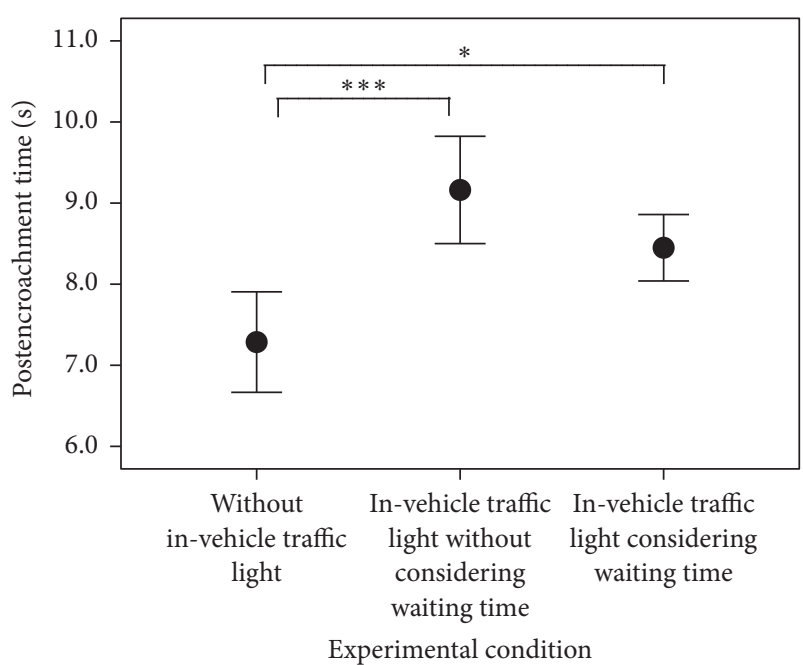

(a)

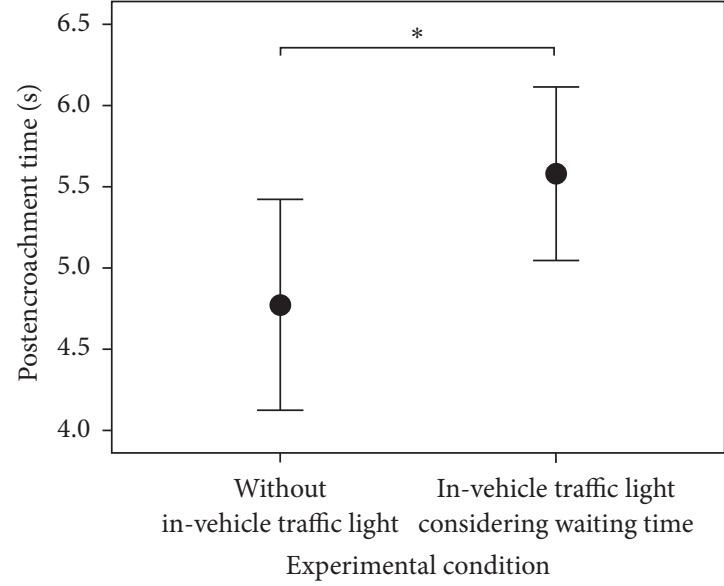

(b)

FIGURE 8: Results of the postencroachment time: (a) minor-road experiment; (b) major-road experiment. $* * *$ and $*$ indicate a significant difference at $p<0.001$ and $p<0.05$ in statistical analysis, respectively.

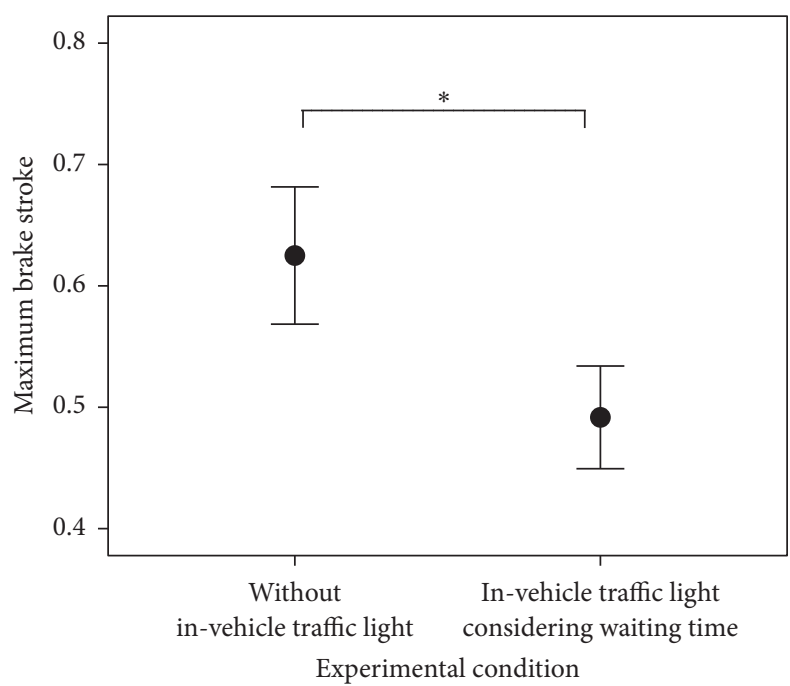

FIGURE 9: Results of the maximum brake stroke in the major-road experiment. $*$ indicates a significant difference at $p<0.05$ in statistical analysis.

Figure 11 shows that the participants felt significantly more frustrated when there was no in-vehicle traffic light than when the in-vehicle traffic light without considering the waiting time was applied $(p=0.002<0.05)$. Moreover, the feeling of frustration was significantly less for the provision of the in-vehicle traffic light considering the waiting time than for the provision of the in-vehicle traffic light without considering the waiting time $(p<0.001)$.

4.2.2. Evaluation of Task Difficulty. The difficulties of completing the same driving task under different assistance conditions were evaluated in the minor-road experiment. Figure 12 shows that although the participants were required

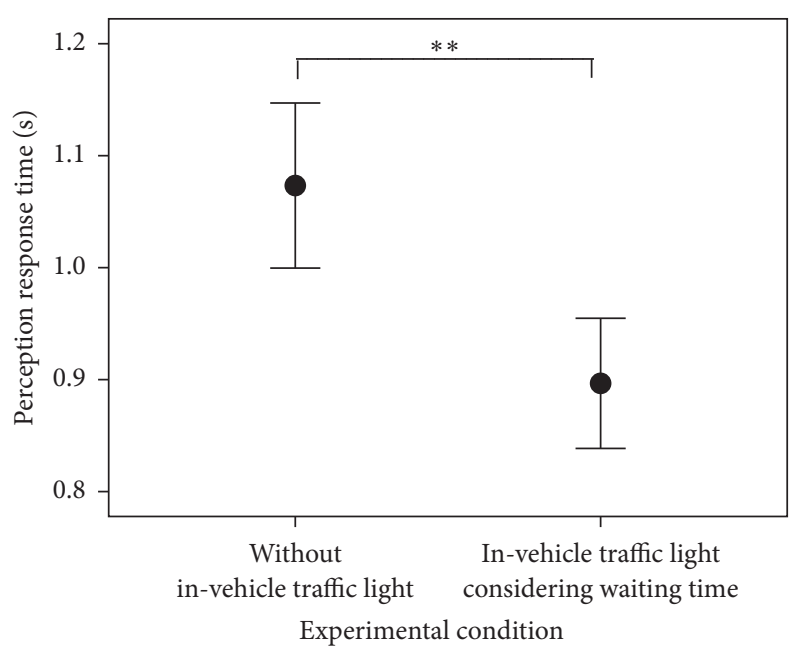

FIGURE 10: Results of the perception response time in the majorroad experiment. $* *$ indicates a significant difference at $p<0.01$ in statistical analysis.

to turn right at the same intersection, they felt that it was significantly more difficult to complete the driving task without the in-vehicle traffic light than under the other two conditions $(p<0.001)$. No significant difference in task difficulty evaluation was observed between the cases of invehicle traffic lights with and without the consideration of waiting time.

4.2.3. Evaluation of Safety. Figure 13 presents the results of the driving safety evaluation of major-road drivers in the major-road experiment. A significant difference was observed between the conditions of no in-vehicle traffic light and the provision of the in-vehicle traffic light considering the waiting time $(p<0.001)$, indicating that the participants 


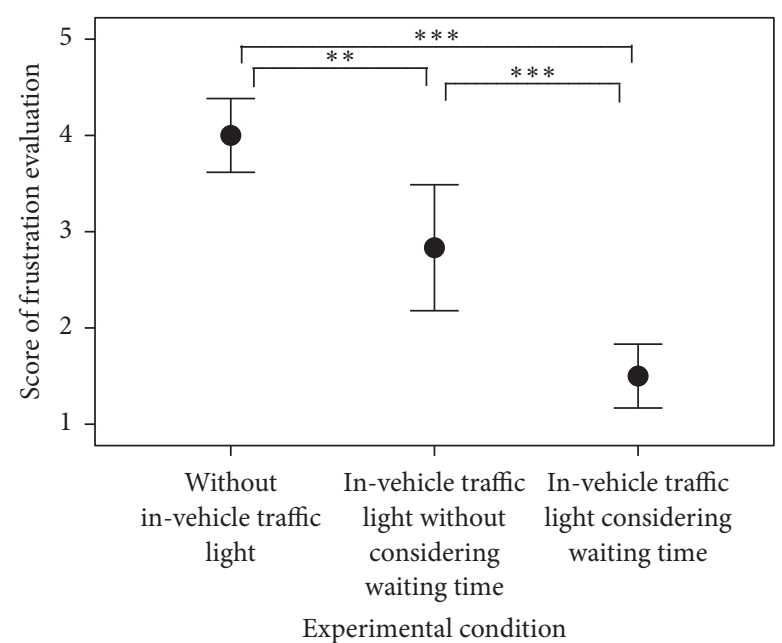

Figure 11: Scores of frustration evaluation in the minor-road experiment, ranging from 1 to 5: $1=$ very low, $2=$ low, $3=$ average, $4=$ high, and $5=$ very high. $* * *$ and $* *$ indicate a significant difference at $p<0.001$ and $p<0.01$ in statistical analysis, respectively.

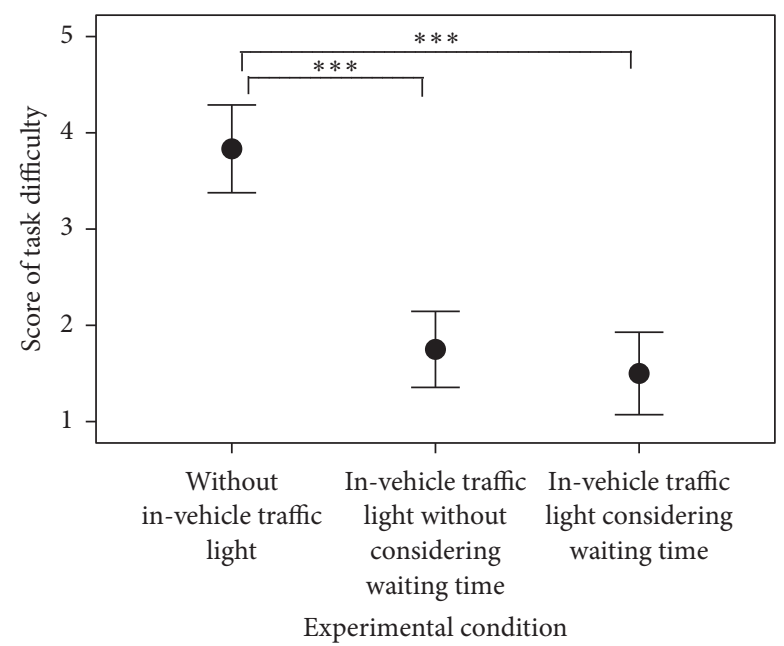

FIGURE 12: Scores of task difficulty evaluation in the minor-road experiment, ranging from 1 to 5: $1=$ very low, $2=$ low, 3 = average, 4 $=$ high, and $5=$ very high. $* * *$ indicates a significant difference at $p<0.001$ in statistical analysis.

felt safer when assisted by the in-vehicle traffic light with consideration of the waiting time.

\section{Discussions}

It was expected that the driving experiences of minor-road vehicles would be improved through the consideration of waiting time in the implementation of an in-vehicle traffic light, without detriment to the driving safety of major-road vehicles. The experimental results were thus carefully analyzed, and several interesting results were found to deserve further discussion.

Figure 5 showed that the application of the in-vehicle traffic light considering the waiting time significantly reduced

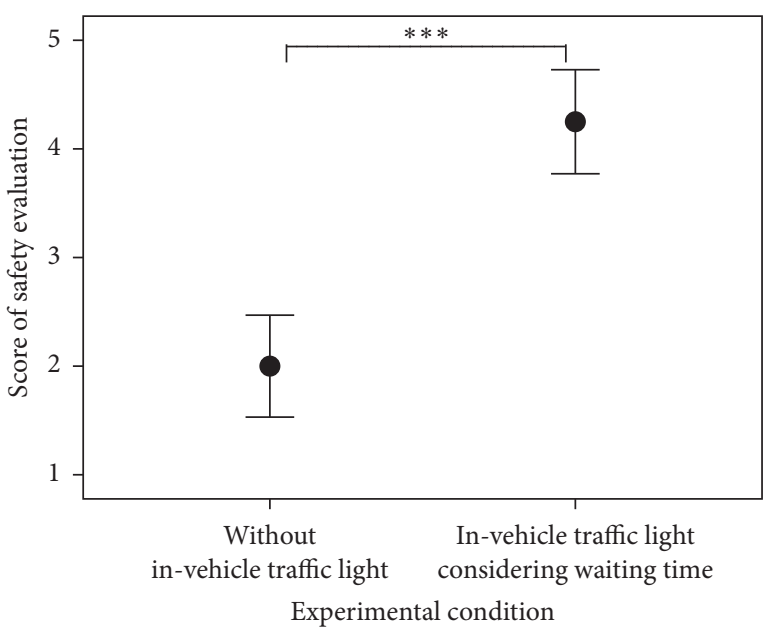

FIGURE 13: Scores of safety evaluation in the major-road experiment, ranging from 1 to $5: 1=$ very low, $2=$ low, $3=$ average, $4=$ high, and $5=$ very high. $* * *$ indicates a significant difference at $p<0.001$ in statistical analysis.

the maximum acceleration stroke of minor-road vehicles. It was revealed that the consideration of waiting time might be effective in preventing the aggressive driving of minorroad vehicles. Previous studies pointed out that accelerationrelated indexes, including maximum acceleration, are suitable for evaluating aggressive or emotional driving [31, 32]. As for the cause of aggressive driving, it was reported that aggressive driving was more likely to occur in situations of dense traffic [33]. In the minor-road experiment, the continuous major-road traffic flow was considered challenging for the minor-road drivers, which might result in aggressive driving. Meanwhile, it has been demonstrated that challenging or unexpected traffic situations can induce frustration and other negative emotional states [34]. According to the frustration-aggression hypothesis, the frustration of drivers might also lead to risky and aggressive driving behaviors, including strong acceleration $[35,36]$.

Frustration was evaluated in the blink rate analysis and subjective evaluations. It was reported that the blink rate was highly related to the dopaminergic systems and the mental states including frustration might be effectively analyzed with the blink rate $[37,38]$. The blink rate was, therefore, analyzed according to the hypothesis that the feeling of frustration can be detected by monitoring the blink rate [39]. Normally, the average blink rate is around 14 blinks per minute [40]. During the minor-road experiment, the measured blink rates ranged from 12 to 22 blinks per minute and are therefore considered reliable for evaluation. Moreover, previous studies suggested that the blink rate might increase with the level of frustration [41, 42]. According to the subjective evaluation of frustration, as shown in Figure 11, drivers felt less frustrated when provided with the in-vehicle traffic light with consideration of the waiting time than when provided with the in-vehicle traffic light without consideration of the waiting time, which coincided with the blink rate analysis. However, no significant difference in the blink rate was 
observed between the conditions of no provision of the invehicle traffic light and the provision of the in-vehicle traffic light without considering the waiting time, although the participants reported more frustration without the in-vehicle traffic light in their subjective evaluation. This is considered due to the task difficulty. As presented in Figure 12, the participants reported that it was more difficult to complete the driving task without the in-vehicle traffic light, and it has been suggested that the blink rate tends to decrease if the task difficulty increases [43].

The maximum lateral acceleration was significantly lower when the in-vehicle traffic light was provided while considering the waiting time than when the in-vehicle traffic light was provided without considering the waiting time as shown in Figure 7 . The result suggests that the steering stability of minor-road vehicles is improved by considering the waiting time when using the in-vehicle traffic light. It has been suggested that lower maximum lateral acceleration corresponds to less deviation from the idealized curved path during a turn at an intersection [44].

The major-road experiment was performed to evaluate the driving safety of major-road drivers. A critical part of driving safely is the ability to detect and respond to emergency traffic hazards. The entry of minor-road vehicles in the major-road experiment was considered an emergency hazard, and the perception response time was therefore used to analyze the detection and response ability of major-road drivers. As shown in Figure 10, when there was no in-vehicle traffic light, the perception response time ranged from 1.01 to $1.15 \mathrm{~s}$. When the in-vehicle traffic light considering the waiting time was applied, the perception response time decreased and ranged from 0.84 to $0.96 \mathrm{~s}$. It has been reported that the mean value of the perception response time is around $1 \mathrm{~s}$ [45]. Meanwhile, in analyzing the duration of a driver's perception response to intruding vehicles at intersections, another study found that the mean time from the start of motion until brake pedal application was $1.14 \mathrm{~s}$, which was in accordance with the results when no in-vehicle traffic light was applied [46, 47]. It is noted that, with the provision of the in-vehicle traffic light, the major-road drivers had an advantage in detecting the entry of minor-road vehicles, as they would be immediately warned once other vehicles started entering intersections. Moreover, as presented in Figure 9, the maximum brake stroke significantly decreased with the provision of in-vehicle traffic light. It has been demonstrated that vehicle performance might deteriorate with an increase in the brake stroke [48]. The analysis of driving operations revealed that a longer postencroachment time could be achieved with a smaller maximum brake stroke by applying the in-vehicle traffic light, which suggested that the safety of major-road drivers might be ensured. Furthermore, as shown in Figure 13, the subjective evaluation of driving safety was also in accordance with the results obtained based on the driving operations.

As a limitation of the study, the practical application of the proposed in-vehicle traffic light is still needed to be studied with a large random sample, which can truly represent the driver population in reality. Actually, to represent the true driver population, a variety of factors should be taken into consideration, including gender, age, driving experience, education background, and personal characteristics [49-51]. Meanwhile, the practical application of the in-vehicle traffic light requires the deployment of vehicular communication devices for all the vehicles, and it is a difficult task to provide the same driving conditions for every participant in an actual vehicle experiment. Therefore, this study was mainly executed with a driving simulator to analyze the influences of waiting time on driver behaviors, while using the in-vehicle traffic light at priority-controlled intersections. On the other hand, considering the limited experimental conditions in this study, the acceptable sample of participants was determined to satisfy the requirement of sufficient statistical power [52]. Statistical power is the likelihood of finding statistically significant differences given that statistically significant differences actually do exist [53]. It depends on three factors: alpha level, effect size, and sample size. In this study, the alpha level and sample size were set as 0.05 and 12 , respectively. Therefore, the statistical power could be estimated based on the effect size, which was related to the mean values and standard deviations. Based on the calculated results of SPSS and a widely accepted calculation method [54], the statistical power of this study was around 0.8 , which was acceptable for consideration in general studies $[55,56]$.

\section{Conclusion}

Given the application of vehicular communications, the present study proposed an in-vehicle traffic light system with the consideration of waiting time to assist drivers in crossing priority-controlled unsignalized intersections. Moreover, to evaluate the effects of the waiting time on driver behaviors, two driving simulator experiments were performed with 12 participants for minor-road and major-road cases.

In the minor-road case, the application of an in-vehicle traffic light considering the waiting time significantly reduced the maximum acceleration stroke and blink rate, indicating that the aggressive driving of minor-road vehicles might be successfully avoided with such application. Meanwhile, a significant decrease was observed in the maximum lateral acceleration with the consideration of waiting time, showing that better steering stability might be achieved.

In the major-road case, it was observed that the postencroachment time significantly increased and the perception response time significantly decreased when applying the invehicle traffic light while considering the waiting time. The results indicate that the in-vehicle traffic light might enhance the drivers' ability to detect the entry of other vehicles, which would contribute to safe driving. According to the results of postencroachment time, it is believed that the driving safety of major-road drivers can be ensured when the in-vehicle traffic light is applied while considering the waiting time.

The present study may contribute to the development of driver assistance systems at priority-controlled unsignalized intersections and provide useful references for further applications of V-2-X communications in intelligent transportation systems. The proposed system will be implemented with a real vehicle in future work. 


\section{Conflicts of Interest}

The authors declare that there are no conflicts of interest regarding the publication of this article.

\section{Acknowledgments}

This study was supported by the Next-Generation Energies for Tohoku Recovery Project.

\section{References}

[1] National Highway Traffic Safety Administration, Fatality Anal$y$ sis and Reporting System, U. S. Department of Transportation, Washington, D. C., USA, 2014.

[2] B. Yang, R. Zheng, K. Shimono, T. Kaizuka, and K. Nakano, "Evaluation of the effects of in-vehicle traffic lights on driving performances for unsignalised intersections," IET Intelligent Transport Systems, vol. 11, no. 2, pp. 76-83, 2017.

[3] B. Yang, R. Zheng, and K. Nakano, "Application of in-vehicle traffic lights for improvement of driving safety at unsignalized intersections," in Proceedings of the IEEE Intelligent Vehicles Symposium, IV 2015, pp. 628-633, Seoul, Korea, July 2015.

[4] D. Max, S. Craig, J. W. Nicolas, and C. Janet, Intersection Decision Support: an Overview Report \#6 in the Series: Developing Intersection Decision Support Solutions, University of Minnesota, 2007.

[5] R. David, A. Sofia, E. S. Steven, A. M. James, and Y. C. Ching, "Gap acceptance for vehicles turning left across on-coming traffic: implications for intersection decision support design," in Proceedings of the Transportation Research Board 85th Annual Meeting, pp. 1-25, Washington, D. C., USA, 2006.

[6] National Highway Traffic Safety Administration, Traffic Safety Facts 2014, U.S. Department of Transportation, Washington, D. C., USA, 2016.

[7] National Cooperative Highway Research Program, NCHRP Report 500, Vol. 5: a Guide for Addressing Unsignalized Intersection Collisions, Transportation Research Board, 2003.

[8] J.-A. Jang, K. Choi, and H. Cho, "A fixed sensor-based intersection collision warning system in vulnerable line-of-sight and/or traffic-violation-prone environment," IEEE Transactions on Intelligent Transportation Systems, vol. 13, no. 4, pp. 18801890, 2012.

[9] J. Fischer, A. Menon, A. Gorjestani, C. Shankwitz, and M. Donath, "Range sensor evaluation for use in cooperative intersection collision avoidance systems," in Proceedings of the 2009 IEEE Vehicular Networking Conference, VNC 2009, Tokyo, Japan, October 2009.

[10] M. P. Van, "Correlation of design and control characteristics with accidents at rural multi-lane highway intersections in Indiana: interim report," Tech. Rep. FHWA/IN/JHRP-77/22, Joint Highway Research Project, Indiana Department of Transportation and Purdue University, West Lafayette, Ind, USA, 1977.

[11] T. Streubel and K. H. Hoffmann, "Prediction of driver intended path at intersections," in Proceedings of the 25th IEEE Intelligent Vehicles Symposium (IV'14), pp. 134-139, IEEE, Dearborn, Mich, USA, June 2014.

[12] G. Burchett and T. Maze, "Rural expressway intersections that contribute to reduced safety performance," in Proceedings of the Mid-Continent Transportation Research Symposium, pp. 1-14, Ames, Iowa, USA, 2005.
[13] O. K. Tonguz, "Notice of violation of IEEE publication principles biologically inspired solutions to fundamental transportation problems," IEEE Communications Magazine, vol. 490, no. 11, pp. 106-115, 2011.

[14] M. Ferreira, R. Fernandes, H. Conceição, W. Viriyasitavat, and O. K. Tonguz, "Self-organized traffic control," in Proceedings of the 7th ACM International Workshop on VehiculAr InterNETworking (VANET '10), pp. 85-89, Chicago, Ill, USA, September 2010.

[15] B. Yang, R. Zheng, Y. Yin, S. Yamabe, and K. Nakano, "Analysis of influence on driver behaviour while using in-vehicle traffic lights with application of head-up display," IET Intelligent Transport Systems, vol. 10, no. 5, pp. 347-353, 2016.

[16] M. Ferreira and P. M. D'Orey, "On the impact of virtual traffic lights on carbon emissions mitigation," IEEE Transactions on Intelligent Transportation Systems, vol. 13, no. 1, pp. 284-295, 2012.

[17] C. O. Monreal, P. Gomes, M. K. Silvéria, and M. Ferreira, "In-vehicle virtual traffic lights, a graphical user interface," in Proceedings of the 7th Iberian Conference on Information Systems and Technologies, pp. 1-6, Madrid, Spain, 2012.

[18] H. Conceicao, M. Ferreira, and P. Steenkiste, "Virtual traffic lights in partial deployment scenarios," in Proceedings of the 2013 IEEE Intelligent Vehicles Symposium, IEEE IV 2013, pp. 988-993, Gold Coast, Australia, June 2013.

[19] Transportation Research Board, "Highway Capacity Manual," fifth edition, Washington, D. C., USA, pp. 1-1650, 2010.

[20] J. M. Bunker, "Novel methods and the maximum likelihood estimation technique for estimating traffic critical gap," Journal of Advanced Transportation, vol. 48, no. 6, pp. 542-555, 2014.

[21] K. Fitzpatrick, "Gaps accepted at stop-controlled intersections," Transportation Research Record, vol. 1303, no. 11, pp. 103-112, 1991.

[22] S. M. Tupper, M. A. Knodler, and D. S. Hurwitz, "Connecting gap acceptance behavior with crash experience," in Proceedings of the 3rd International Conference on Road Safety and Simulation, pp. 1-18, Indianapolis, Ind, USA, 2011.

[23] J. Thakonlaphat and S. Kazushi, "Effect of waiting time on the gap acceptance behavior of u-turning vehicles at midblock median openings," Journal of the Eastern Asia Society for Transportation Studies, vol. 9, pp. 1601-1613, 2011.

[24] I. A. O. Turki and S. E. Mohammad, "Gap acceptance behavior at u-turn median openings - case study in Jordan," Jordan Journal of Civil Engineering, vol. 7, no. 3, pp. 332-341, 2013.

[25] S. Nabaee, An Evaluation of Gap Acceptance Behavior at Unsignalized Intersections, Oregon State University, 2011.

[26] S. M. Tupper, Safety and Operational Assessment of Gap Acceptance through Large-Scale Field Evaluation, University of Massachusetts Amherst, 2014.

[27] “Japan Automobile Manufacturers Association," Guidelines for In-Vehicle Display Systems-Version 3.0, pp. 1-15, Tokyo, Japan, 2004.

[28] W. K. M. Alhajyaseen, "The development of conflict index for the safety assessment of intersections considering crash probability and severity," in Proceedings of the 5th International Conference on Ambient Systems, Networks and Technologies, ANT 2014 and 4th International Conference on Sustainable Energy Information Technology, SEIT 2014, pp. 364-371, bel, June 2014.

[29] Indicators for traffic safety assessment and prediction and their application in micro-simulation modelling: a study of urban 
and suburban intersections [ph.D thesis], Royal Institute of Technology, 2005.

[30] L. Peesapati, M. Hunter, and M. Rodgers, "Evaluation of postencroachment time as surrogate for opposing left-turn crashes," Transportation Research Record, no. 2386, pp. 42-51, 2013.

[31] E. Roidl, B. Frehse, and R. Höger, "Emotional states of drivers and the impact on speed, acceleration and traffic violations a simulator study," Accident Analysis \& Prevention, vol. 70, pp. 282-292, 2014.

[32] A. N. Stephens and J. A. Groeger, "Situational specificity of trait influences on drivers' evaluations and driving behaviour," Transportation Research Part F: Traffic Psychology and Behaviour, vol. 12, no. 1, pp. 29-39, 2009.

[33] D. Waard, K. Brookhuis, and A. Toffetti, Developments in Human Factors in Transportation, Design, and Evaluation, Shaker Publishing, Maastricht, the Netherlands, 2006.

[34] Y.-C. Lee and F. K. Winston, "Stress induction techniques in a driving simulator and reactions from newly licensed drivers," Transportation Research Part F: Traffic Psychology and Behaviour, vol. 42, pp. 44-55, 2016.

[35] H. S. Friedman and M. W. Schustack, Personality: classic Theories and Modern Research, Pearson, London, UK, 5th edition, 2010.

[36] G. M. Björklund, "Driver irritation and aggressive behaviour," Accident Analysis \& Prevention, vol. 40, no. 3, pp. 1069-1077, 2008.

[37] S. Thibaud, K. Rana, and H. Niels, "Mental state analysis using blink rate," Article ID 20140200417, US patent, US 20140200417 A1, 2014.

[38] H. Siiri, Neural responses to observed eye blinks in normal and slow motion: an MEG study [m.s. Thesis], University of Helsinki, 2012.

[39] B. R. N. Ramachandran, P. S. A. Romero, J. Born, S. Winkler, and R. Ratnam, "Measuring neural, physiological and behavioral effects of frustration," in Proceedings of the 16th International Conference on Biomedical Engineering, pp. 43-46, Singapore, 2016.

[40] M. J. Doughty and T. Naase, "Further analysis of the human spontaneous eye blink rate by a cluster analysis-based approach to categorize individuals with 'normal' versus 'frequent' eye blink activity," Fırat Sağlık Hizmetleri Dergisi, vol. 32, no. 6, pp. 294-299, 2006.

[41] K. Fukuda, "Eye blinks: New indices for the detection of deception," International Journal of Psychophysiology, vol. 40, no. 3, pp. 239-245, 2001.

[42] M. Al-Abdulmunem and S. T. Briggs, "Spontaneous blink rate of a normal population sample," International Contact Lens Clinic, vol. 26, no. 2, pp. 29-32, 1999.

[43] J. Oh, S.-Y. Jeong, and J. Jeong, "The timing and temporal patterns of eye blinking are dynamically modulated by attention," Human Movement Science, vol. 31, no. 6, pp. 1353-1365, 2012.

[44] S. Classen, O. Shechtman, B. Stephens et al., "The impact of roadway intersection design on driving performance of young and senior adults," Traffic Injury Prevention, vol. 8, no. 1, pp. 6977, 2007.

[45] J. K. Caird, S. L. Chisholm, C. J. Edwards, and J. I. Creaser, "The effect of yellow light onset time on older and younger drivers' perception response time (PRT) and intersection behavior," Transportation Research Part F: Traffic Psychology and Behaviour, vol. 10, no. 5, pp. 383-396, 2007.
[46] D. V. McGehee, E. N. Mazzae, G. H. S. Baldwin et al., "Examination of drivers' collision avoidance behavior using conventional and antilock brake systems on the Iowa driving simulator," National Highway Traffic Safety Administration, pp. 1-102, 1999, Washington, D. C., USA.

[47] E. N. Mazzae, F. S. Barickman, G. Forkenbrock, G. H. Baldwin, and S., "NHTSA light vehicle antilock brake system research program task 5.2/5.3: test track examination of drivers' collision avoidance behavior using conventional and antilock brakes," National Highway Traffic Safety Administration, pp. 1-161, 2003.

[48] S. G. Roberts and T. D. Day, "Integrating design and virtual test environments for brake component design and material selection," SAE Technical Papers, 2000.

[49] A. N. Stephens and M. Fitzharris, "Validation of the driver behaviour questionnaire in a representative sample of drivers in Australia," Accident Analysis \& Prevention, vol. 86, pp. 186-198, 2016.

[50] F. Sagberg, "Road accidents caused by drivers falling asleep," Accident Analysis \& Prevention, vol. 31, no. 6, pp. 639-649, 1999.

[51] B. Woodrow and A. D. Thomas, Human Factors in Intelligent Transportation Systems, Psychology Press, 1st edition, 1997.

[52] M. Kumar and G. S. Rao, Statistical Techniques for Transportation Engineering, Butterworth-Heinemann, 1st edition, 2017.

[53] E. Bradley, Research and Evaluation in Counseling (Research, Statistics, \&Amp; Program Evaluation), Wadsworth Publishing, 1st edition, 2007.

[54] S. Chow, J. Shao, and H. Wang, Sample Size Calculations in Clinical Research, Chapman \& Hall/CRC Biostatistics Series, 2nd edition, 2007.

[55] J. Cohen, "A power primer," Psychological Bulletin, vol. 112, no. 1, pp. 155-159, 1992.

[56] B. M. Scott, "Sample size required for adverse impact analysis," Applied HRM Research, vol. 6, no. 1, pp. 13-32, 2001. 


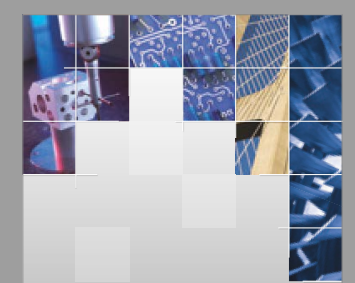

\section{Enfincering}
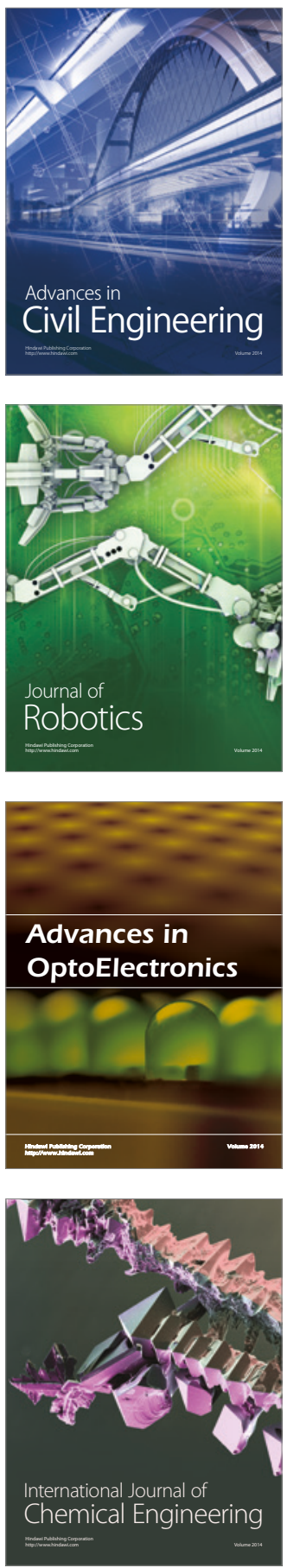

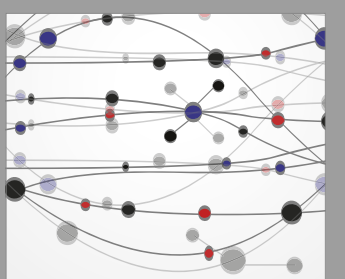

The Scientific World Journal

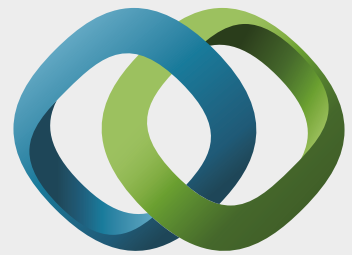

\section{Hindawi}

Submit your manuscripts at

https://www.hindawi.com
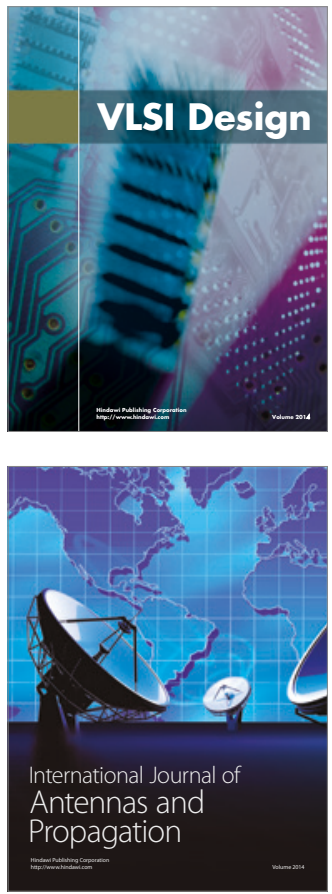

\section{Rotating}

Machinery
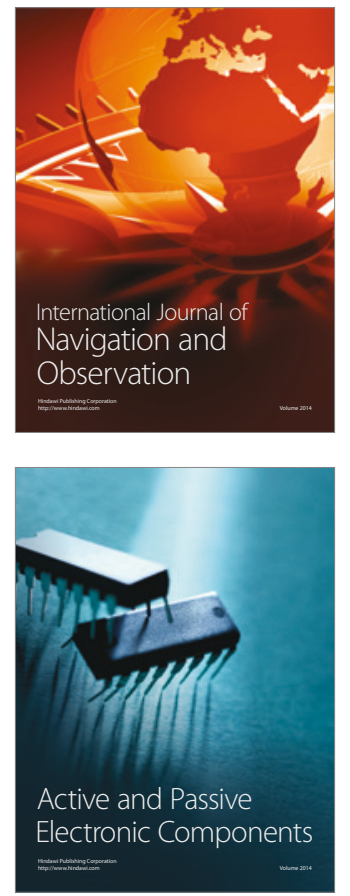
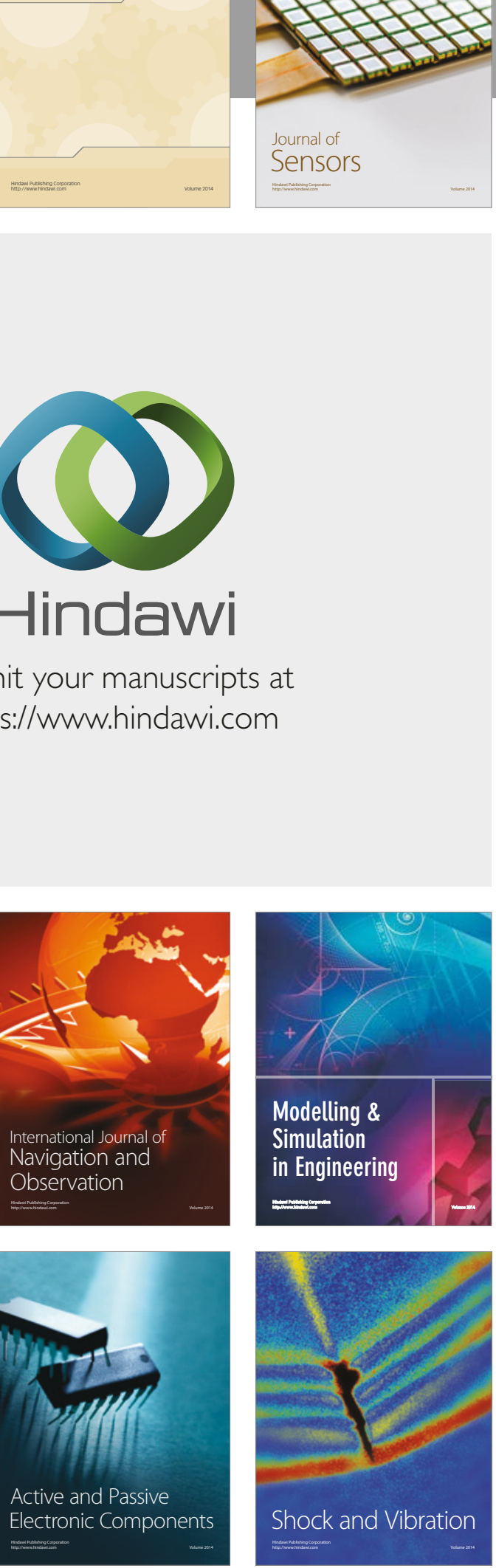
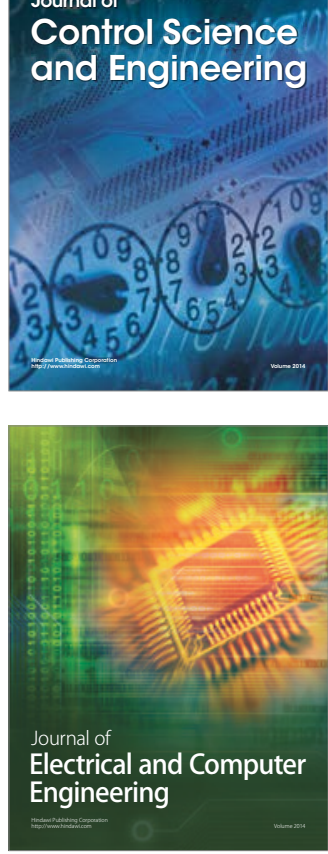

Distributed

Journal of

Control Science

and Engineering
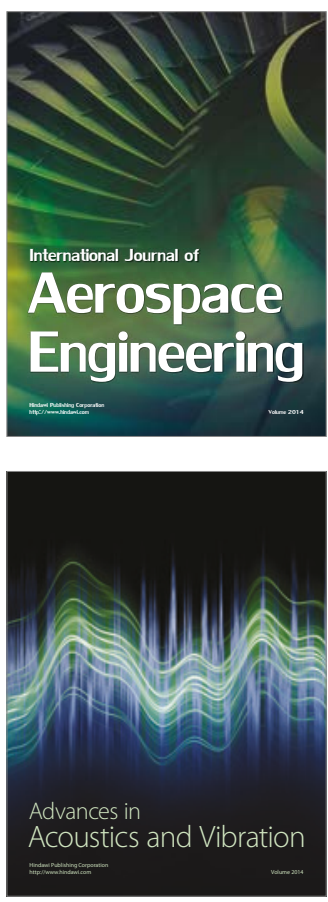

Sensor Networks 